\title{
The Acceptance of Key Public Health Interventions by the Polish Population Is Related to Health Literacy, But Not eHealth Literacy
}

\author{
Mariusz Duplaga \\ Department of Health Promotion and e-Health, Institute of Public Health, Faculty of Health Sciences, \\ Jagiellonian University Medical College, Grzegórzecka Str. 20, 31-531 Krakow, Poland; \\ mariusz.duplaga@uj.edu.pl
}

Received: 8 July 2020; Accepted: 27 July 2020; Published: 29 July 2020

\begin{abstract}
Background: Public health and health promotion rely on many different interventions, which range from health education and communication, through community mobilisation and changes to environmental conditions, to legal and fiscal actions. The introduction of the increased tax on sugar-sweetened beverages (SSB), popularly called sugar tax (ST), and a mandatory programme of vaccinations are the strategies inciting the most vivid discussions in Polish society. The study was intended to assess the determinants of the attitudes of Polish society regarding the ST and to vaccinations. Methods: For the analysis, the data originating from the survey of a representative adult sample of Polish society $(n=1000)$ was used. The survey was based on computer-assisted telephone interviewing (CATI). The assessment of the relationships between the selected variables and the opinions about the introduction of the ST and the safety and effectiveness of vaccinations were carried out using the $\mathrm{chi}^{2}$ test and univariate logistic regression models. Results: The acceptance of the ST and vaccination showed a significant relationship to the level of health literacy (HL) but not to eHealth literacy (eHL). Respondents having a higher rather than lower HL; older rather than younger; married rather than singles; retired, or on a disability pension, rather than vocationally active and nonusers of the Internet rather than users were more likely to show an acceptance for both interventions. Those more frequently using health care services and those with chronic diseases showed a greater belief in the safety and effectiveness of vaccinations. Conclusions: The relationship between the opinions of the two public health interventions analysed and the sociodemographic variables demonstrated similar patterns. Interestingly, the opinions were associated only with HL and not with eHL and users of the Internet were more sceptical about the interventions.
\end{abstract}

Keywords: sugar tax; vaccination; health literacy; eHealth literacy

\section{Introduction}

The concept of health literacy (HL) is of crucial importance for health promotion. The definition of health literacy proposed by the World Health Organisation (WHO) belongs to the most popular [1]. It is clear that a focus on the ability to access and use health-related information is essential, but these are not the only aspects of health literacy. The definition proposed by the WHO puts the emphasis, not only on the cognitive, but also on social skills. The context of HL is usually associated with the readiness of people to safeguard their health and to manage their contacts with the health care system. There is growing evidence that insufficient HL may be associated with many unfavourable effects. These include displaying unhealthy behaviours [2,3], lower attention to preventive actions [4], lower knowledge about the disease, not following the physician's recommendations and limited understanding of the treatment regimen [5-7], worse control of the disease [8], and even, a higher 
risk of hospitalisation and mortality [9]. Some authors also indicated that the lower HL of people is associated with higher expenditure on health care [10].

The concept of digital HL or eHealth literacy (eHL) is used in parallel. It is related to the accessing, understanding, appraisal and application of health-related information available from digital resources [11]. Considering that the Internet is currently one of the primary sources of health information, the role of eHL seems to be obvious; however, the relationship between HL and eHL is not entirely clear. According to Norman and Skinner, HL is one of the types of literacy needed for developing eHL [11]. The correlation between both types of literacy, as substantiated in some studies, is at a level of $0.4[12,13]$. However, the association between eHL and health behaviours or clinical outcomes is not so well documented as it is for HL.

Some authors emphasise a broader meaning of HL going beyond the individual context. According to Baur, a health literate society should be able to create better public health [14]. Such a perception of health literacy which is a precondition of public health actions, resulted in the call to establish the concept of "public health literacy". According to Freedman et al. (2009), individuals who demonstrate such health literacy, are able to consider and act on health concerns in a community context [15]. The association between HL and the attitudes to community- or nation-wide public health policies has not been frequently examined.

From the onset, health promotion has been proposed as a doctrine combining a whole array of strategies including, not only the development of individual skills, but also the formation of supportive environments, the mobilisation of the community, reorientation of health care services and the shaping of public health policies [16]. It is evident that health promotion relies on many forms of interventions, even if the role of health education and health communication has been frequently overemphasised. However, it appears that in certain circumstances, educational efforts may provide an inadequate response to public health challenges and governments must, therefore, apply legal and fiscal interventions. In many countries, vaccination programmes are mandatory [17]. The taxes or duties imposed on alcohol and tobacco products remain one of the most obvious examples of fiscal measures intended to moderate their consumption [18]. In the last decade, the tax applied to products with a high sugar content became a favoured tool to reduce the harmful effect of sugar-sweetened beverages (SSB) on obesity [19].

The immunisation schedule requires mandatory vaccinations against tuberculosis, hepatitis B, diphtheria, tetanus, pertussis, poliomyelitis, Haemophilus influenzae type $b$, pneumococci, measles, mumps and rubella in Poland [20]. The National Institute of Public Health's 2018 Annual Report indicated that depending on the voivodeship, $87.3 \%$ to $96.4 \%$ of children aged three had been vaccinated against measles, mumps and rubella. However, between 2012 and 2018, the number of Polish parents who refused to accept the vaccination programmes available to their children has increased significantly, from 5340 to 48,609 [21]. This is commonly associated with the influence of antivaccination movements that incite doubts about the safety and effectiveness of vaccines [22]. In 2019, after a discussion lasting several years, the government prepared legislation for a special tax to be imposed on SSB in response to the growing rates of obesity in Polish society. To date, no research has been undertaken to find if HL may be linked to the acceptance of such public health interventions which have triggered significant public debate. The main aim of this study was to assess the association between HL and eHL with the opinions about vaccinations and the introduction of the ST held by a representative sample of the adult Polish population. The role of other variables, including the utilisation of health care resources, the use of information technologies and the sociodemographic characteristics were also analysed.

\section{Materials and Methods}

\subsection{Survey}

The analysis was based on the data obtained from a survey carried out on a representative sample of the adult Polish population $(n=1000)$. The participants of the survey were recruited by the Biostat 
Company (Biostat Sp. z o.o., Rybnik, Poland) which has extensive experience in conducting opinion polls [23]. The survey was undertaken using the computer-assisted telephone interviewing (CATI) technique and was completed in one week in mid-December 2016. The sample group was selected by the stratified proportional sampling of the database of mobile and stationary phone numbers developed by the Biostat Company. The survey was carried out with a 58 -item questionnaire, including a 16-item short version of the Health Literacy Survey Questionnaire (HLS-EU-Q16) [24]; an 8-item Polish version of the eHealth Literacy Scale (Pl-eHEALS) [25,26] and a set of the items asking about the utilisation of health care resources; health status; the use of the Internet; opinions on public health interventions and sociodemographic characteristics. More details on the sampling procedure and the structure of the questionnaire is available elsewhere [3].

\subsection{Statistical Analysis}

Statistical analysis was performed with IBM SPSS v.24 software (IBM Corp. Armonk, NY, USA). Descriptive statistics were calculated for the variables used in the analysis; absolute and relative frequencies for categorical variables and mean and standard deviation for continuous variables. Chi2 test and univariate logistic regression models were used to assess the association between variables reflecting the opinions about vaccinations and the introduction of the ST as well as potential determinants. In the case of continuous variables, the differences between categories were assessed with either the Student's t-test or the U Mann-Whitney test, depending on the distribution of the variable. For independent variables used in the univariate logistic regression models, odds ratio (OR) and $95 \%$ confidence intervals $(95 \%)$ were calculated.

\subsection{Variables}

The dependent variables used in the logistic regression were developed after dichotomisation of the two items asking respondents for their opinions about (1) the safety and effectiveness of vaccination, and (2) the introduction of the sugar tax. The initial responses to these items were ranked on a 5-point Likert scale from "I decidedly agree" to "I decidedly do not agree" with a neutral option in the middle. The responses "I decidedly agree" and "I agree" were coded as " 1 ", other answers as " 0 ".

Independent variables used in the logistic regression models included the sociodemographic variables (sex, age, level of education, place of residence, net household income, marital status and vocational activity), the utilisation of health care services (visits to health care facilities, hospitalisations), health status (self-assessed health status, the prevalence of chronic diseases), the use of information technologies (IT; Internet and smartphone use), health literacy (HL) and e-health literacy (eHL). The HL score was calculated according to the guidelines given in the European Health Literacy Survey project [24]. The total score was calculated only if there were at least 14 meaningful responses to the individual questions. The response options "very difficult" and "difficult "were assigned with value " 0 " and "easy" and "very easy" with value "1". The total score ranged from 0-16 [3,24]. The eHL score was calculated as the sum of individual scores after assigning values from 1 to 5 to the response options (from "decidedly not" to "decidedly yes"). The minimum total eHEALS that could be achieved was 0 and the maximum was 40 .

Respondents filled the questionnaire anonymously after obtaining the information about the study and confirming they agree to participate. The study was conducted in accordance with the Declaration of Helsinki, and the protocol was approved by the Bioethical Committee at Jagiellonian University (No. 122.6120.313.2016 from November 24, 2016).

\section{Results}

\subsection{Characteristics of the Study Group}

The characteristic of the study group is shown in Table 1. Its sociodemographic structure corresponds with that of the general population at the same time. The mean age was 45.87 (16.16). 
An HL score could be calculated for the 842 respondents; the mean value (standard deviation, SD) was 12.99 (3.11). The eHL score was calculated only for Internet users $(n=849)$ as 28.91 (5.36). Furthermore, $37.3 \%$ of the respondents were convinced that the introduction of the ST was an appropriate measure to reduce obesity in society, $22.6 \%$ were undecided and $40.2 \%$ did not agree. In turn, $64.4 \%$ of respondents believed that vaccines are safe and effective for preventing infectious diseases, $23.1 \%$ were unsure, and only $12.5 \%$ expressed a negative opinion.

\subsection{The Opinion about the Safety and Effectiveness of Vaccinations}

The respondents convinced of the safety and effectiveness of vaccinations achieved higher HL scores than those expressing the opposite opinion (mean (SD), 13.15 (3.03) vs. 12.70 (3.24), U Mann-Whitney test, $p=0.046)$. In the univariate logistic model, an increase of HL score of one point was associated with a $5 \%$ increase in the probability of a positive opinion (OR, 95\% CI: 1.05, 1.001-1.10). The opinion was not related to the eHL score (OR, 95\% CI: 0.99, 0.97-1.01). The results of chi ${ }^{2}$ tests and univariate logistic regression modelling for the opinion about vaccination as a dependent variable are presented in Table 2.

Among sociodemographic variables, there was a significant association between the opinion and age, marital status and vocational status. Older respondents were more convinced about the safety and effectiveness of vaccinations (mean age (SD): 48.20 (15.68) vs. 41.67 (16.18), Student's t-test, $p<0.001)$. With every year of age, there was a $3 \%$ increase in positive opinions about vaccinations (OR, 95\% CI: 1.03, 1.02-1.04). Married persons were more than two times more likely to appreciate vaccinations than singles (OR, 95\% CI: 2.23, 1.67-2.27) and widowed persons, divorced or separated nearly 2.5 times (OR, 95\% CI: 2.45, 1.57-3.82). As for the vocational status, the employees of public or private entities were less likely to have a positive opinion than those on retirement or those receiving a disability pension (OR, 95\% CI: 1.76, 1.27-2.44) but more likely than university students or pupils (OR, 95\% CI: 0.54, 0.34-0.86). The analysis based on the chi2 test has not shown any association between the opinions about vaccinations and the place of residence. Nevertheless, the univariate regression model confirmed that respondents living in urban areas with a population of 100,000-200,000, were less convinced about the safety and effectiveness of vaccinations than those living in rural areas (OR, 95\% CI: 0.60, 0.39-0.92).

The opinion expressed about vaccinations was also associated with the number of visits to health care institutions in the preceding year. Those that had to make visits most frequently in the preceding year (at least six or more times) were nearly twice as likely to express a positive opinion about vaccinations (OR, 95\% CI: 1.86, 1.22-2.83). A positive opinion was also associated with a higher prevalence of chronic diseases and with an unsatisfactory self-assessment of health status. The respondents who suffered from one or more chronic diseases were more inclined to appreciate vaccinations (OR, 95\% CI: 1.44, 1.07-1.96 and 1.63, 1.12-2.36, respectively). The persons who assessed their health status as very good or perfect were nearly $50 \%$ less likely to express a positive opinion than persons unsatisfied with their health (OR, 95\% CI: 0.55, 0.33-0.91). The users of both the Internet and smartphones were less positive about vaccinations (OR, 95\% CI: 0.56, 0.38-0.83 and 0.48, 0.27-0.84).

\subsection{The Attitude towards the Introduction of the Sugar Tax}

There was a statistically significant association between the HL score and the attitude towards the introduction of the sugar tax. With an increase of the HL score by one point, the probability of a positive opinion increased by $8 \%$ (OR, 95\% CI: 1.08, 1.03-1.13; Table 3). In turn, there was no significant association between the eHL score and this opinion (OR, 95\% CI: 1.01, 0.99-1.03). 
Table 1. Characteristics of the study group.

\begin{tabular}{|c|c|c|}
\hline Variable & Response Categories & Number of Subjects \% (n) \\
\hline \multirow{2}{*}{ Sex } & Male & $47.7(477)$ \\
\hline & Female & $52.3(523)$ \\
\hline \multirow{4}{*}{ Education level } & Lower than upper secondary & $17.9(179)$ \\
\hline & Upper secondary or postsecondary nontertiary & $43.5(435)$ \\
\hline & Bachelor's degree & $12.2(122)$ \\
\hline & Masters' degree or higher & $26.4(264)$ \\
\hline \multirow{5}{*}{ Place of residence } & Rural & $28.3(283)$ \\
\hline & Urban $<20,000$ & $13.4(134)$ \\
\hline & Urban from 20,000 to $<100,000$ & $25.5(255)$ \\
\hline & Urban from 100,000 to $<200,000$ & $13.4(134)$ \\
\hline & Urban from 200,000 & $19.4(194)$ \\
\hline \multirow{3}{*}{ Marital status } & Single & $29.0(290)$ \\
\hline & Widowed, divorced or separated & $13.0(130)$ \\
\hline & Married & $58.0(580)$ \\
\hline \multirow{4}{*}{ Household net monthly income } & $\leq 1500 \mathrm{PLN}^{*}$ & $23.9(239)$ \\
\hline & 1500-2500 PLN & $22.8(228)$ \\
\hline & $>2500$ PLN & $40.9(409)$ \\
\hline & Refused to disclose & $12.4(124)$ \\
\hline \multirow{5}{*}{ Vocational status } & Employee & $43.9(439)$ \\
\hline & Self-employed or farmer & $10.7(107)$ \\
\hline & Retired or on a disability pension & $28.0(280)$ \\
\hline & University or school student & $8.4(84)$ \\
\hline & Unemployed & $9.0(90)$ \\
\hline \multirow{4}{*}{ Visits to health care institution in the preceding 12 months } & Not used & $15.6(156)$ \\
\hline & $1-2$ times & $35.0(350)$ \\
\hline & $3-5$ times & $23.2(232)$ \\
\hline & $>5$ times & $24.2(242)$ \\
\hline \multirow{2}{*}{ Admitted to hospital in the preceding 12 months } & No & $83.6(836)$ \\
\hline & Yes & $16.4(164)$ \\
\hline
\end{tabular}


Table 1. Cont.

\begin{tabular}{|c|c|c|}
\hline Variable & Response Categories & Number of Subjects \% (n) \\
\hline \multirow{4}{*}{ Chronic disease } & No & $49.8(498)$ \\
\hline & One disease & $29.8(298)$ \\
\hline & $>1$ disease & $17.8(178)$ \\
\hline & Difficult to say & $2.6(26)$ \\
\hline \multirow{4}{*}{ Self-assessment of health status } & Unsatisfactory & $9.8(98)$ \\
\hline & Satisfactory & $23.8(238)$ \\
\hline & Good & $44.8(448)$ \\
\hline & Very good or perfect & $21.6(216)$ \\
\hline \multirow{2}{*}{ Internet use } & No & $15.1(151)$ \\
\hline & Yes & $84.9(849)$ \\
\hline \multirow{3}{*}{ The use of mobile telephony } & Nonuser & $7.4(74)$ \\
\hline & Mobile phone but not a smartphone & $28.4(284)$ \\
\hline & Smartphone & $64.2(642)$ \\
\hline \multirow{5}{*}{ Introduction of the sugar tax } & I decidedly do not agree & $16.4(164)$ \\
\hline & I do not agree & $23.8(238)$ \\
\hline & Difficult to say & $22.6(226)$ \\
\hline & I agree & $28.0(280)$ \\
\hline & I decidedly agree & $9.2(92)$ \\
\hline \multirow{5}{*}{ Vaccines are safe and effective } & I decidedly do not agree & $4.5(45)$ \\
\hline & I do not agree & $8.0(80)$ \\
\hline & Difficult to say & $23.1(231)$ \\
\hline & I agree & $47.5(475)$ \\
\hline & I decidedly agree & $16.9(169)$ \\
\hline
\end{tabular}

* PLN—current ISO4217 code for Polish zloty. 
Table 2. The determinants of the opinion about the safety and effectiveness of vaccinations.

\begin{tabular}{|c|c|c|c|c|c|c|c|}
\hline \multirow[t]{2}{*}{ Independent Variable } & \multirow[t]{2}{*}{ Categories of the Independent Variable } & \multicolumn{2}{|c|}{$\begin{array}{c}\text { Safety and Effectiveness of } \\
\text { Vaccinations }\end{array}$} & \multirow[t]{2}{*}{$p$-Value * } & \multirow{2}{*}{ OR } & \multirow{2}{*}{$95 \% \mathrm{CI}$} & \multirow{2}{*}{$p$-Value \& } \\
\hline & & No & Yes & & & & \\
\hline \multirow{2}{*}{ Sex } & Male $^{\#}$ & $37.1(177)$ & $62.9(300)$ & \multirow{2}{*}{0.34} & 1 & & \\
\hline & Female & $34.2(179)$ & $65.8(344)$ & & 0.34 & $0.88-1.50$ & 0.34 \\
\hline \multirow{4}{*}{ Education level } & Lower than upper secondary $\#$ & $30.7(55)$ & $69.3(124)$ & \multirow{4}{*}{0.28} & 1 & & \\
\hline & Upper secondary or postsecondary nontertiary & $34.7(151)$ & $65.3(284)$ & & 0.83 & $0.57-1.21$ & 0.34 \\
\hline & Bachelor's degree & $39.3(48)$ & $60.7(74)$ & & 0.68 & $0.42-1.11$ & 0.12 \\
\hline & Masters' degree or higher & $38.6(102)$ & $61.4(162)$ & & 0.70 & $0.47-1.05$ & 0.088 \\
\hline \multirow{5}{*}{ Place of residence } & Rural \# & $30.7(87)$ & $69.3(196)$ & \multirow{5}{*}{0.21} & 1 & & \\
\hline & Urban $<20,000$ & $36.6(49)$ & $63.4(85)$ & & 0.77 & $0.50-1.19$ & 0.24 \\
\hline & Urban from 20,000 to $<100,000$ & $36.1(92)$ & $63.9(163)$ & & 0.78 & $0.55-1.13$ & 0.19 \\
\hline & Urban from 100,000 to $<200,000$ & $42.5(57)$ & $57.5(77)$ & & 0.60 & $0.39-0.92$ & 0.018 \\
\hline & Urban from 200,000 & $36.6(71)$ & $63.5(123)$ & & 0.77 & $0.52-1.13$ & 0.18 \\
\hline \multirow{3}{*}{ Marital status } & Single $\#$ & $49.3(143)$ & $50.7(147)$ & \multirow{3}{*}{$<0.001$} & 1 & & \\
\hline & Widowed, divorced or separated & $28.5(37)$ & $71.5(93)$ & & 2.45 & $1.57-3.82$ & $<0.001$ \\
\hline & Married & $30.3(176)$ & $69.7(404)$ & & 2.23 & $1.67-2.99$ & $<0.001$ \\
\hline \multirow{4}{*}{ Household net monthly income } & $\leq 1500 \mathrm{PLN}^{\#}$ & $33.1(79)$ & $66.9(160)$ & \multirow{4}{*}{0.066} & 1 & & \\
\hline & 1500-2500 PLN & $30.3(69)$ & $69.7(159)$ & & 1.14 & $0.77-1.68$ & 0.52 \\
\hline & $>2500$ PLN & $37.9(155)$ & $62.1(254)$ & & 0.81 & $0.58-1.13$ & 0.22 \\
\hline & Refusal & $42.7(53)$ & $57.3(71)$ & & 0.66 & $0.42-1.03$ & 0.07 \\
\hline \multirow{5}{*}{ Vocational status } & Employed $^{\#}$ & $38.3(168)$ & $61.7(271)$ & \multirow{5}{*}{$<0.001$} & 1 & & \\
\hline & Self-employed or farmer & $33.6(36)$ & $66.4(71)$ & & 1.22 & $0.78-1.91$ & 0.38 \\
\hline & Retired or on a disability pension & $26.1(73)$ & $73.9(207)$ & & 1.76 & $1.27-2.44$ & 0.001 \\
\hline & University or school student & $53.6(45)$ & $46.4(39)$ & & 0.54 & $0.34-0.86$ & 0.010 \\
\hline & Unemployed & $37.8(34)$ & $62.2(56)$ & & 1.02 & $0.64-1.63$ & 0.93 \\
\hline \multirow{4}{*}{$\begin{array}{c}\text { The use services of the health } \\
\text { institution in the } \\
\text { preceding } 12 \text { months }\end{array}$} & Not used \# & $43.6(68)$ & $56.4(88)$ & \multirow{4}{*}{0.034} & 1 & & \\
\hline & $1-2$ times & $36.3(127)$ & $63.7(223)$ & & 1.36 & $0.92-1.99$ & 0.12 \\
\hline & $3-5$ times & $34.5(80)$ & $65.5(152)$ & & 1.47 & $0.97-2.23$ & 0.071 \\
\hline & $>5$ times & $29.3(71)$ & $70.7(171)$ & & 1.86 & $1.22-2.83$ & 0.004 \\
\hline
\end{tabular}


Table 2. Cont

\begin{tabular}{|c|c|c|c|c|c|c|c|}
\hline \multirow[t]{2}{*}{ Independent Variable } & \multirow[t]{2}{*}{ Categories of the Independent Variable } & \multicolumn{2}{|c|}{$\begin{array}{l}\text { Safety and Effectiveness of } \\
\text { Vaccinations }\end{array}$} & \multirow[t]{2}{*}{$p$-Value * } & \multirow[t]{2}{*}{ OR } & \multirow[t]{2}{*}{$95 \% \mathrm{CI}$} & \multirow[t]{2}{*}{$p$-Value ${ }^{\&}$} \\
\hline & & No & Yes & & & & \\
\hline \multirow{2}{*}{ Admission to hospital } & $\mathrm{No}^{\#}$ & $35.3(295)$ & $64.7(541)$ & \multirow{2}{*}{0.64} & 1 & & \\
\hline & Yes & $37.2(61)$ & $62.8(103)$ & & 0.92 & $0.65-1.30$ & 0.64 \\
\hline \multirow{3}{*}{ Chronic disease } & $\mathrm{No}^{\#}$ & $39.6(197)$ & $60.4(301)$ & \multirow{3}{*}{0.008} & 1 & & \\
\hline & 1 disease & $31.2(93)$ & $68.8(205)$ & & 1.44 & $1.07-1.96$ & 0.018 \\
\hline & $>1$ disease & $28.7(51)$ & $71.3(127)$ & & 1.63 & $1.12-2.36$ & 0.010 \\
\hline \multirow{4}{*}{ Self-assessment of health status } & Unsatisfactory ${ }^{\#}$ & $29.6(29)$ & $70.4(69)$ & \multirow{4}{*}{0.009} & 1 & & \\
\hline & Satisfactory & $29.4(70)$ & $70.6(168)$ & & 1.01 & $0.60-1.69$ & 0.97 \\
\hline & Good & $36.4(163)$ & $63.6(285)$ & & 0.74 & $0.46-1.18$ & 0.20 \\
\hline & Very good or perfect & $43.5(94)$ & $56.5(122)$ & & 0.55 & $0.33-0.91$ & 0.020 \\
\hline \multirow{2}{*}{ Internet use } & $\mathrm{No}^{\#}$ & $25.2(38)$ & $74.8(113)$ & \multirow{2}{*}{0.004} & 1 & & \\
\hline & Yes & $37.5(318)$ & $62.5(531)$ & & 0.56 & $0.38-0.83$ & 0.004 \\
\hline \multirow{3}{*}{ The use of mobile telephony } & Nonuser \# & $23.0(17)$ & $77.0(57)$ & \multirow{3}{*}{0.013} & 1 & & \\
\hline & Mobile phone but not a smartphone & $32.4(92)$ & $67.6(192)$ & & 0.62 & $0.34-1.13$ & 0.12 \\
\hline & Smartphone & $38.5(247)$ & $61.5(395)$ & & 0.48 & $0.27-0.84$ & 0.010 \\
\hline Age $^{\$}$ & & 41.67 (16.18) & $48.20(15.68)$ & $<0.001$ & 1.03 & $1.02-1.04$ & $<0.001$ \\
\hline HL score ${ }^{\$}$ & & $12.70(3.24)$ & $13.15(3.03)$ & 0.046 & 1.05 & $1.001-1.10$ & 0.046 \\
\hline eHL score $^{\$}$ & & $27.94(5.95)$ & $27.60(6.43)$ & 0.89 & 0.99 & $0.97-1.01$ & 0.42 \\
\hline
\end{tabular}

* $p$-value for chi2 test in case of categorical variables, for the Student's $t$-test in case of age, and U Mann-Whitney test in case of health literacy (HL) and eHealth literacy (eHL) scores;

$\& p$-value for univariate logistic regression; ${ }^{\$}$ for age, HL and eHL scores-mean (standard deviation) was provided depending on the category of the opinion about vaccinations; ${ }^{\#}$ reference

category of the independent variable in the logistic regression model. 
Table 3. The determinant of the opinion about the introduction of the sugar tax.

\begin{tabular}{|c|c|c|c|c|c|c|c|}
\hline \multirow[t]{2}{*}{ Independent Variable } & \multirow[t]{2}{*}{ Categories of the Independent Variable } & \multicolumn{2}{|c|}{$\begin{array}{c}\text { Acceptance of the Introduction } \\
\text { of the Sugar Tax }\end{array}$} & \multirow[t]{2}{*}{$p^{*}$} & \multirow{2}{*}{ OR } & \multirow{2}{*}{$95 \%$ CI } & \multirow{2}{*}{$p^{\&}$} \\
\hline & & No & Yes & & & & \\
\hline \multirow{2}{*}{ Sex } & Male \# & $62.5(298)$ & $37.5(179)$ & \multirow{2}{*}{0.84} & 1 & & \\
\hline & Female & $63.1(330)$ & $36.9(193)$ & & 0.97 & $0.75-1.26$ & 0.84 \\
\hline \multirow{4}{*}{ Education level } & Lower than upper secondary \# & $60.9(109)$ & $39.1(70)$ & \multirow{4}{*}{0.43} & 1 & & \\
\hline & Upper secondary or postsecondary nontertiary & $65.3(284)$ & $34.7(151)$ & & 0.83 & $0.58-1.19$ & 0.30 \\
\hline & Bachelor's degree & $63.9(78)$ & $36.1(44)$ & & 0.88 & $0.55-1.41$ & 0.59 \\
\hline & Masters' degree or higher & $59.5(157)$ & $40.5(107)$ & & 1.06 & $0.72-1.56$ & 0.76 \\
\hline \multirow{5}{*}{ Place of residence } & Rural \# & $59.7(169)$ & $40.3(114)$ & \multirow{5}{*}{0.29} & 1 & & \\
\hline & Urban $<20,000$ & $64.2(86)$ & $35.8(48)$ & & 0.83 & $0.54-1.27$ & 0.38 \\
\hline & Urban from 20,000 to $<100,000$ & $65.1(166)$ & $34.9(89)$ & & 0.80 & $0.56-1.13$ & 0.20 \\
\hline & Urban from 100,000 to $<200,000$ & $57.5(77)$ & $42.5(57)$ & & 1.10 & $0.72-1.67$ & 0.66 \\
\hline & Urban from 200,000 & $67.0(130)$ & $33.0(64)$ & & 0.73 & $0.50-1.07$ & 0.11 \\
\hline \multirow{3}{*}{ Marital status } & Single \# & $72.8(211)$ & $27.2(79)$ & \multirow{3}{*}{$<0.001$} & 1 & & \\
\hline & Widowed, divorced or separated & $59.2(77)$ & $40.8(53)$ & & 1.84 & $1.19-2.84$ & 0.006 \\
\hline & Married & $58.6(340)$ & $41.4(240)$ & & 1.89 & $1.39-2.56$ & $<0.001$ \\
\hline \multirow{4}{*}{ Household net monthly income } & $\leq 1500$ PLN $^{\#}$ & $62.3(149)$ & $37.7(90)$ & \multirow{4}{*}{0.66} & 1 & & \\
\hline & 1500-2500 PLN & $66.2(151)$ & $33.8(77)$ & & 0.84 & $0.58-1.23$ & 0.38 \\
\hline & $>2500$ PLN & $61.9(253)$ & $38.1(156)$ & & 1.02 & $0.74-1.42$ & 0.90 \\
\hline & Refusal & $60.5(75)$ & $39.5(49)$ & & 1.08 & $0.69-1.69$ & 0.73 \\
\hline \multirow{5}{*}{ Vocational status } & Employed \# & $63.6(279)$ & $36.4(160)$ & \multirow{5}{*}{0.001} & 1 & & \\
\hline & Self-employed or farmer & $60.7(65)$ & $39.3(42)$ & & 1.13 & $0.73-1.74$ & 0.59 \\
\hline & Retired or on a disability pension & $55.4(155)$ & $44.6(125)$ & & 1.41 & $1.04-1.91$ & 0.029 \\
\hline & University or school student & $81.0(68)$ & $19.0(16)$ & & 0.41 & $0.23-0.73$ & 0.003 \\
\hline & Unemployed & $67.8(61)$ & $32.2(29)$ & & 0.83 & $0.51-1.34$ & 0.45 \\
\hline \multirow{4}{*}{$\begin{array}{l}\text { The use services of the health } \\
\text { institution in the } \\
\text { preceding } 12 \text { months }\end{array}$} & Not used $\#$ & $65.4(102)$ & $34.6(54)$ & \multirow{4}{*}{0.93} & 1 & & \\
\hline & $1-2$ times & $62.6(219)$ & $37.4(131)$ & & 1.13 & $0.76-1.68$ & 0.54 \\
\hline & $3-5$ times & $62.9(146)$ & $37.1(86)$ & & 1.11 & $0.73-1.70$ & 0.62 \\
\hline & $>5$ times & $62.4(151)$ & $37.6(91)$ & & 1.14 & $0.75-1.73$ & 0.55 \\
\hline
\end{tabular}


Table 3. Cont.

\begin{tabular}{|c|c|c|c|c|c|c|c|}
\hline \multirow[t]{2}{*}{ Independent Variable } & \multirow[t]{2}{*}{ Categories of the Independent Variable } & \multicolumn{2}{|c|}{$\begin{array}{c}\text { Acceptance of the Introduction } \\
\text { of the Sugar Tax }\end{array}$} & \multirow[t]{2}{*}{$p^{*}$} & \multirow[t]{2}{*}{ OR } & \multirow[t]{2}{*}{$95 \%$ CI } & \multirow[t]{2}{*}{$p^{\&}$} \\
\hline & & No & Yes & & & & \\
\hline \multirow{2}{*}{ Admitted to hospital } & $\mathrm{No}^{\#}$ & $62.2(520)$ & $37.8(316)$ & \multirow[b]{2}{*}{0.38} & 1 & & \\
\hline & Yes & $65.9(108)$ & $34.1(56)$ & & 0.85 & $0.60-1.21$ & 0.38 \\
\hline \multirow{3}{*}{ Chronic disease } & No $\#$ & $64.7(322)$ & $35.3(176)$ & \multirow{3}{*}{0.31} & 1 & & \\
\hline & 1 disease & $61.7(184)$ & $38.3(114)$ & & 1.13 & $0.84-1.53$ & 0.41 \\
\hline & $>1$ disease & $58.4(104)$ & $41.6(74)$ & & 1.30 & $0.92-1.85$ & 0.14 \\
\hline \multirow{4}{*}{ Self-assessment of health status } & Unsatisfactory \# & $68.4(67)$ & $31.6(31)$ & \multirow{4}{*}{0.04} & & & \\
\hline & Satisfactory & $55.0(131)$ & $45.0(107)$ & & 1.77 & $1.08-2.90$ & 0.025 \\
\hline & Good & $61.8(277)$ & $38.2(171)$ & & 1.33 & $0.84-2.13$ & 0.23 \\
\hline & Very good or perfect & $70.8(153)$ & $29.2(63)$ & & 0.89 & $0.53-1.49$ & 0.66 \\
\hline \multirow[b]{2}{*}{ Internet use } & $\mathrm{No}^{\#}$ & $53.0(80)$ & $47.0(71)$ & \multirow[b]{2}{*}{0.007} & 1 & & \\
\hline & Yes & $64.5(548)$ & $35.5(301)$ & & 0.62 & $0.44-0.88$ & 0.007 \\
\hline \multirow{3}{*}{ The use of mobile telephony } & Nonuser $\#$ & $55.4(41)$ & $44.6(33)$ & \multirow{3}{*}{0.034} & 1 & & \\
\hline & Mobile phone but not a smartphone & $58.1(165)$ & 41.9 (119) & & 0.90 & $0.54-1.50$ & 0.68 \\
\hline & Smartphone & $65.7(422)$ & $34.3(220)$ & & 0.65 & $0.40-1.05$ & 0.080 \\
\hline Age $^{\$}$ & & $44.20(16.02)$ & $48.70(16.01)$ & $<0.001$ & 1.02 & $1.01-1.03$ & $<0.001$ \\
\hline HL score $^{\$}$ & & $12.74(3.27)$ & $13.41(2.77)$ & 0.005 & 1.08 & $1.03-1.13$ & 0.003 \\
\hline eHL score ${ }^{\$}$ & & $27.85(6.71)$ & $27.65(5.99)$ & 0.16 & 1.01 & $0.99-1.03$ & 0.62 \\
\hline
\end{tabular}

${ }^{*} p$-value for chi2 test in case of categorical variables, for the Student's $t$-test in case of age, and U Mann-Whitney test in case of HL and eHL scores; ${ }^{\&} p$-value for univariate logistic

regression; $\$$ for age, HL and eHL scores-mean (standard deviation) was provided depending on the category of the opinion about vaccinations; ${ }^{\#}$ reference category of the independent

variable in the logistic regression model. 
The opinion about the ST showed a similar pattern of the associations with sociodemographic factors as with the opinions about vaccinations. Older persons were more likely to be positive about the ST (OR, 95\% CI: 1.02, 1.01-1.03). Singles were less inclined to express a positive opinion than married persons (OR, 95\% CI: 1.89, 1.39-2.56) widowed, divorced or separated persons (OR, 95\% CI: 1.84, 1.19-2.84). Retired persons, or on a disability pension, were more in favour of the sugar tax than employees (OR, 95\% CI: 1.41, 1.04-1.91) but students and pupils were less in favour (OR, 95\% CI: 0.41, 0.23-0.73).

There was no association between the variables reflecting the utilisation of health care services and the opinion about the introduction of the ST. Interestingly, the highest acceptance was shown by the persons assessing their health as satisfactory $(45.0 \%)$ and the lowest by those assessing it as very good or perfect $(29.2 \%)$ or as unsatisfactory $(31.6 \%)$. The univariate regression model showed that there was a significant difference only for the comparison of persons assessing their health as satisfactory and unsatisfactory (OR, 95\% CI: 1.77, 1.08-2.90). Finally, the chi ${ }^{2}$ test indicated a significant association both between the opinion about the ST and the use of the Internet $(p=0.007)$ or a smartphone $(p=0.034)$. The association was maintained for Internet use only in the univariate regression model. Internet users less frequently agreed that vaccines are safe and effective (OR, 95\% CI: 0.62, 0.44-0.88).

\section{Discussion}

In Poland, the majority of the population $(64.4 \%)$ would appear to believe that vaccination is a safe and effective method of preventing infectious diseases. Only $12.5 \%$ of the respondents were sceptical about vaccines. However, only $37 \%$ of respondents believed that the introduction of the ST was an appropriate measure to limit the prevalence of obesity, but $40 \%$ were of the opposite opinion. The analysis showed that the attitude towards crucial public health interventions depends on a person's level of HL but not on their eHL. Furthermore, older persons, married people and the retired or receivers of disability pensions more frequently showed acceptance both for the introduction of the $\mathrm{ST}$ and vaccinations than, respectively, younger persons, single people and employees. The users of the Internet and smartphones were less inclined to accept such interventions as were those who self-assessed their health as very good or perfect. Persons with chronic disease or those who declared more frequent visits to health care institutions were more likely to appreciate vaccinations, but not the ST.

According to the WHO Working Group on Vaccine Hesitancy, there is a very extensive list of determinants of vaccine hesitancy. These may be divided into three domains: firstly influences arising from historical, sociocultural, environmental, health system/institutional economic and political factors; secondly, influences stemming from the personal perception of a vaccine or the social environment, and finally, issues related directly to vaccines and vaccination [27]. This reported survey was mainly focused on the sociodemographic characteristics, the utilisation of health care services and the use of IT.

It seems that the general attitude towards vaccination has been rarely researched. Eilers et al. have confirmed that the acceptance for several types of vaccines is higher among persons of 65 years and older than among those aged 50-65 [28]. A study carried out in Italy showed that vaccine hesitancy was associated with perceived economic hardship and actual refusal with a lower level of parental education [29]. Greater age, receiving information on vaccinations from a physician and the higher quality of such information as well as better knowledge about vaccines were associated with a more positive attitude towards vaccination in a mixed group of Polish pupils, students, patients, parents and healthcare professionals [30].

Most studies reporting on the variables related to the opinions of the general public, or specific populations, about vaccinations are focused on particular types of vaccines. Novak et al. analysed the data from the 2016 National Survey of U.S. Adults [31] and assessed the acceptance of influenza vaccination based on actual vaccination rates. They found that the highest rates of acceptance were by non-Hispanic Whites and Blacks and those aged 65 years and older. The systematic review on influenza vaccination in high-income countries carried out by Lucyk et al. showed that higher socioeconomic 
status assessed based on education, income, social class, occupation and the level of deprivation was associated with higher levels of influenza vaccination [32].

Mat et al. published a systematic review of acceptance factors of pneumococcal vaccination among the adult population [33]. According to these authors, there were three groups of factors influencing acceptance: the provider's domain, patients' perception and sociodemographic factors. In some studies, the group of sociodemographic factors, gender and age were reported to show a significant association with the acceptance of vaccination. Higher acceptance was found among women than men and by those aged at least 65 years old. Another study performed in the USA, limited to the population of adults aged 65 or above, revealed that the uptake of the pneumococcal vaccine was lower among: those of black and Hispanic ethnicity, than among non-Hispanic whites; by the poor rather than those with the highest income; among those with a low level of education than among those with at least college education and finally among those living in rural communities or urban inner-city areas, rather than those living in suburban areas [34].

According to the systematic review published by Lopez et al., higher acceptance of human papillomavirus (HPV) vaccine was associated most consistently with female gender and younger age of respondent parent, female gender of the adolescent, higher household income and previous childhood vaccinations [35]. A recent study by Polla et al. revealed that among parents, those who were unmarried were more likely to be hesitant about the importance of HPV vaccination [36].

The analysis reported in this paper showed that a higher level of HL was reflected in a higher acceptance of vaccinations. Consistently, according to the systematic review published by Berkman et al. in 2011, low HL was related to a lower probability of accepting influenza immunisations [4]. However, the results of the systematic review focused on the relationship between HL and attitudes towards various types of vaccinations, published by Lorini et al. in 2018 [37], revealed a more complex picture. The authors included only nine studies in their analysis of respondents representing diverse groups; four studies were undertaken on parents of children who received vaccinations, two among adult citizens, one among adults aged 65 years or more, one among females attending college and one among Hispanic females. The studies yielded unequivocal findings, especially in relation to parents' attitudes. In the study performed in Israel, higher communicative and critical HL of parents was associated with a greater likelihood of not vaccinating their children [38]. In the study among Dutch parents, all respondents were willing to vaccinate their children against rotavirus when the vaccine was supplied within the National Immunization Programme, but only by those with lower levels of education and lower HL when the vaccine was to be provided by the free market [39]. Another study, performed in the USA, did not find a significant association between maternal HL and the immunisation status of children [40]. In the study carried out in India, higher maternal HL was associated with the likelihood of a child receiving the diphtheria-tetanus-pertussis vaccine [41]. In other groups of respondents, the relation between HL and vaccination uptake varied. Higher HL in the USA increased the likelihood of influenza vaccination among older adults [42,43], and HPV vaccination by undergraduate women [44]. Higher HL was also associated with a higher awareness of HPV and the HPV vaccine by adults in the USA. Additionally, in the USA there was no association between the likelihood of influenza vaccination among adult Hispanic women [45] and adults younger than 40 years [43]. The authors of the systematic review concluded that the role of HL in predicting vaccine hesitancy or acceptance is influenced by various factors including the country, people's age and the type of vaccine [37].

Further studies tend to confirm that the relationship between health literacy and the acceptance of vaccinations is not straightforward and depends on the characteristics of the studied group. In 2018, Castro-Sanchez et al. found a significant association between HL measured with the Short Assessment of Health Literacy for Spanish Adults and the Newest Vital Sign in pregnant women and the vaccination rates against influenza and pertussis [46]. Women rejecting the influenza vaccine had higher HL. Recently, Zhang et al. assessed the relation between HL measured with the standard 47-item version of HLS-EU questionnaire and the attitudes towards vaccination in a group of older adults 65 years 
and greater [47]. They found that lower competencies related to accessing and appraising health information were associated with more significant problems in reaching decisions about vaccination.

The reported study found no significant association between eHL and the acceptance of vaccination, but the use of the Internet and smartphones was related to a lower acceptance. The overview of systematic reviews published in 2018 by Dumit et al. revealed that eHealth interventions and technology might be useful tools for increasing the uptake of immunisations [48]. However, there are few studies which report on a relationship between eHL and the attitudes towards vaccinations. The research performed by Britt et al. on college students, based on the theory of planned behaviour, showed that eHL was positively associated with the intent for HPV vaccination but not with the actual vaccination behaviour [49]. In a later study in a similar group of respondents from 2017, Britt et al. found that eHL was positively associated with beneficial health behaviours identified by the American College Health Association including seeking for the information on vaccinations and also to a smaller degree, undergoing vaccinations, among college students [50].

Additionally, in 2017 Aharony and Goldman reported that parents refusing to vaccinate their children had a higher perceived eHL than hesitant parents or those accepting vaccinations. Additionally, they found that nonrefuser parents had the highest knowledge about vaccinations and the parents refusing vaccinations had the least knowledge [51]. In 2020, Mutur published the results of a survey on eHL and motivators for HPV prevention among young adults in Kenya [52]. She found a positive correlation between eHL and HPV knowledge, perceived risk, self-efficacy and response efficacy. The authors of a systematic review on the association between HL, eHL and health outcomes among patients with long-term conditions found only a few studies in which eHL was assessed [53]. None were related to vaccination attitudes or practices. Currently, eHL as gained new momentum due to the COVID-19 pandemic, but it seems that any high expectations related to its impact on fighting misinformation are yet to be confirmed [54].

The acceptance of the ST has been extensively studied in many countries. In the last decade, surveys carried out in Australia showed that about $40 \%$ to $70 \%$ of the population were in favour of the tax imposed on SSB. In 2012, Morley et al. reported that $69 \%$ of the surveyed participants were in favour of a tax on SSB [55]. Parents were more likely than nonparents and respondents with a higher socioeconomic status, rather than those with a lower status supported a tax on soft drinks and unhealthy food. In 2017 the results of a survey about taxation and nutrition labelling as interventions addressing the incidence of childhood obesity were published [56].

Interestingly, only one-third of respondents strongly supported the introduction of the sugar tax, and $40 \%$ were equivocal about it. The level of acceptance of an SSB tax among parents was related to the household's weekly consumption of soft drinks. In 2018, Sainsbury et al. published the results of an online survey on a nationally representative sample of Australian adults which found that $54.5 \%$ of the participants supported SSB taxation. The binary logistic regression models showed that women more than men, younger rather than older respondents and those with a University degree rather than those who did not complete high school, supported the introduction of the tax [57]. The acceptance of SSB taxation was also reported by Farrell et al. in 2019. According to this team, $42 \%$ of the Australian population were in favour of the tax imposed on SSB and that the greatest opposition to the tax was expressed by the most disadvantaged group [58]. The analysis performed by Miller et al. on the data coming from two surveys: a face-to-face survey conducted in 2014 and CATI survey in 2017, also showed that persons who attained higher levels of education expressed greater support for SSB tax than those with lower levels of education [59]. The acceptance of a sugar tax was frequently much greater if the tax revenue was to be allocated to obesity prevention, subsidies on healthy food or programmes promoting physical activity $[59,60]$.

In June 2017, Belanger-Gravel et al. examined separately support for and the perceived effectiveness of public health interventions aimed at the reduction of obesity among 1000 18-64 years old respondents resident in Quebec, Canada [61]. The introduction of the tax on SSB was strongly supported by $32.8 \%$ 
and somewhat less enthusiastically by a further $27.0 \%$ of respondents. $56.3 \%$ of respondents assessed this intervention as effective.

The survey performed on USA citizens in 2012 by Rivard et al., demonstrated that SSB tax was supported by $36 \%$ of respondents [62]. Greater support was expressed by younger respondents, who had attained higher levels of education and those with body mass index (BMI) $<30 \mathrm{~kg} / \mathrm{m}^{2}$. However, the study published in 2014 by Gollust et al. showed that the tax as a strategy to reduce the consumption of SSB was supported by only $22 \%$ of adult Americans who responded to an online survey [63]. In 2015, Donaldson et al. reported that support for the SSB tax was expressed by $52 \%$ of respondents participating in a telephone-based survey [64]. The support was related to gender, race, political orientation, SSB consumption but not to age, level of education or annual income. In the study performed by Curry et al. on adults in Kansas in 2018, support for a tax on SSB was confirmed by $40 \%$ of respondents, and as in the study of Donaldson et al. it was higher for women and supporters of the Democratic party [65]. In this study, younger respondents were significantly more supportive than older people.

Petrescu et al. in two parallel online surveys compared the acceptability of nudging initiatives aimed at tackling obesity in the UK and USA on samples of 1093 and 1082 respondents, respectively [66]. Taxation intervention was acceptable to $45.5 \%$ of respondents from the UK and $40.7 \%$ from the USA. In the UK sample, the perceived effectiveness of the intervention was the only significant predictor of the acceptance of taxation. Among respondents from the USA, the acceptance was associated with the perceived effectiveness and the belief that the environment is responsible for obesity. A French survey published by Julia et al. in 2015 showed that an ST was perceived as an important measure in improving the health of the population by nearly $58 \%$ of respondents. The support was even higher if the revenues from the tax were to be used for improving the health care system [67]. Contrary to the findings from Australia and the USA, greater support was expressed by the older rather than the younger respondents. Those who reached higher levels of education were also more supportive.

In 2019, Kwon et al. reported the results of a multi-country survey (Australia, Canada, Mexico, UK, USA) to assess public support for food policies promoting healthy diets [68]. They found that taxes on sugary drinks were supported by $30.0 \%$ in the USA to $53.8 \%$ in Mexico. If the revenue raised from the tax were to be spent on subsidising health food, the support would increase considerably to $37.2 \%$ in the USA to $66.3 \%$ in Mexico. An analysis of the determinants in the pooled data from five countries revealed higher support by females than males, older age groups than the youngest groups, and minorities in comparison to the majorities. According to the latest study on public acceptability of an SSB tax in the Netherlands, lower acceptability was associated with a lower educational level, being overweight, moderate or high SSB consumptions and living in a household with adolescents [69].

Finally, the systematic review with a meta-analysis based on 20 papers reporting the results of 22 studies, published in 2019 by Eykelenboom et al., showed that $42 \%$ of the public supported the SSB tax; $39 \%$ accepted it as a measure to reduce obesity, and $66 \%$ supported it if the revenue is used for some type of health-improving initiative [70].

In Poland, contrary to the findings from other countries the sex of respondents was not associated with the acceptance of the sugar tax as a measure to decrease the prevalence of obesity. In many countries, a significant association between age and support for the ST was reported. In Australia and the USA usually, younger respondents revealed higher acceptance than older people. In surveys performed in other countries, as in Poland, older rather than younger respondents were more supportive of the ST. Finally, in many surveys, again contrary to findings from Poland, the level of education was associated with the support for the ST. The results of the survey reported in this paper have not shown a relationship between these variables.

In surveys carried out in other countries, $\mathrm{HL}$, eHL and Internet use were not analysed in respect of the attitude towards sugar taxation. As the penetration of the Internet is growing, and in many societies, the number of nonusers is relatively low, many surveys are performed online. Therefore, the use of the Internet is less frequently considered as a determinant of specific health-related behaviours or 
attitudes. Nonetheless, it may be puzzling why neither HL nor eHL was assessed as a determinant of the acceptance of fiscal interventions to combat the consumption of unhealthy products. It may be related to the fact that $\mathrm{HL}$ is still treated more like a construct reflecting an ability to tackle individual health issues than its relevance to the broader public health context. Interestingly, among the positive impacts of the introduction of a public health Product Tax in Hungary, an improvement of HL was reported [71].

\section{Limitations}

There are some limitations of this study which need to be considered. Initially, although the sample size is sufficient to reflect general trends in the Polish population, it may be too small to clarify the relationships between specific variables. Decidedly, further surveys on large samples would be needed to explain the importance of potential determinants of the attitudes towards specific public health measures. Furthermore, the survey was undertaken using the technique of CATI which may result in less profound consideration of the issues presented in the questionnaire. Finally, the survey was performed at the moment when it was not clear that the government was considering the introduction of the ST. Therefore, for some respondents, the prospect of such a public health intervention could seem very distant, and others would not fully understand its consequences. As for the question about vaccinations, a more targeted approach to the study group probably would be needed as the opinions of parents to the vaccination of their children may be different from the opinions of nonparents or older persons.

\section{Conclusions}

The survey performed on the Polish population showed that there are potentially many variables affecting the opinions regarding the introduction of the ST and the safety and effectiveness of vaccinations. Apart from the sociodemographic factors like age, marital status or vocational status, the utilisation of health care services, the self-perception of health or the prevalence of chronic diseases as well as the use of IT should be considered. Interestingly, it transpired that HL, but not eHL, is related to the acceptance of the ST and vaccination. It may also be surprising that Internet users are more sceptical about such public health interventions. The studies focusing on the relationship between $\mathrm{HL}$ and the acceptance of immunisations undertaken on various populations, and concerning specific types of vaccines, yielded unequivocal results. It seems that higher HL does not necessarily lead to a higher acceptance of vaccinations. It may strongly depend on the characteristics of the surveyed population. Surprisingly, the literature on an association between HL or eHL and the acceptance of public health policies is very limited. There is a scarcity of studies which analyse the relationship between HL, eHL and the attitudes to the sugar tax. One could expect that higher HL and eHL should result in higher support for health-promoting fiscal interventions.

Funding: This research was funded from the statutory project No. N43/DBS/000050 performed in the Department of Health Promotion and e-Health, Institute of Public Health, Faculty of Health Sciences, Jagiellonian University Medical College, Kraków, Poland.

Acknowledgments: The author thanks John R. Blizzard, a retired UK University Senior Lecturer, Chartered Engineer and Churchill Fellow, for proofreading of the manuscript.

Conflicts of Interest: The author declares no conflict of interest.

\section{References}

1. Nutbeam, D.; Kickbusch, I. Health promotion glossary. Health Promot. Int. 1998, 13, 349-364. [CrossRef]

2. Sørensen, K.; Van Den Broucke, S.; Fullam, J.; Doyle, G.; Pelikan, J.; Slonska, Z.; Brand, H. Health literacy and public health: A systematic review and integration of definitions and models. BMC Public Health 2012, 12, 80. [CrossRef] [PubMed]

3. Duplaga, M. Determinants and Consequences of Limited Health Literacy in Polish Society. Int. J. Environ. Res. Public Health 2020, 17, 642. [CrossRef] 
4. Berkman, N.D.; Sheridan, S.L.; Donahue, K.E.; Halpern, D.J.; Crotty, K. Low health literacy and health outcomes: An updated systematic review. Ann. Intern. Med. 2011, 155, 97-107. [CrossRef]

5. Al Sayah, F.; Majumdar, S.R.; Williams, B.; Robertson, S.; Johnson, J.A. Health Literacy and Health Outcomes in Diabetes: A Systematic Review. J. Gen. Intern. Med. 2012, 28, 444-452. [CrossRef] [PubMed]

6. Kale, M.S.; Federman, A.D.; Krauskopf, K.; Wolf, M.; O'Conor, R.; Martynenko, M.; Leventhal, H.; Wisnivesky, J.P. The Association of Health Literacy with Illness and Medication Beliefs among Patients with Chronic Obstructive Pulmonary Disease. PLoS ONE 2015, 10, e0123937. [CrossRef] [PubMed]

7. Cajita, M.I.; Cajita, T.R.; Han, H.R. Health literacy and heart failure a systematic review. J. Cardiovasc. Nurs. 2016, 31, 121-130. [CrossRef]

8. Harrington, K.F.; Zhang, B.; Magruder, T.; Bailey, W.C.; Gerald, L.B. The Impact of Parent's Health Literacy on Pediatric Asthma Outcomes. Pediatr. Allergy Immunol. Pulmonol. 2015, 28, 20-26. [CrossRef]

9. McNaughton, C.D.; Cawthon, C.; Kripalani, S.; Liu, D.; Storrow, A.B.; Roumie, C.L. Health Literacy and Mortality: A Cohort Study of Patients Hospitalized for Acute Heart Failure. J. Am. Heart Assoc. 2015, 4. [CrossRef]

10. Eichler, K.; Wieser, S.; Brügger, U. The costs of limited health literacy: A systematic review. Int. J. Public Health 2009, 54, 313-324. [CrossRef]

11. Norman, C.D.; Skinner, H.A. eHealth literacy: Essential skills for consumer health in a networked world. J. Med. Internet Res. 2006, 8, e9. [CrossRef] [PubMed]

12. Neter, E.; Brainin, E.; Baron-Epel, O. The dimensionality of health literacy and eHealth literacy. Eur. Health Psychol. 2015, 17, 275-280.

13. Duplaga, M.; Grysztar, M.; Tubek, A. The association between health literacy and eHealth literacy in young adult population in Poland. In Proceedings of the European Journal of Public Health, Stockholm, Sweden, 1-4 November 2017.

14. Baur, C. New Directions in Research on Public Health and Health Literacy. J. Health Commun. 2010, 15, 42-50. [CrossRef] [PubMed]

15. Freedman, D.A.; Bess, K.D.; Tucker, H.A.; Boyd, D.L.; Tuchman, A.M.; Wallston, K.A. Public Health Literacy Defined. Am. J. Prev. Med. 2009, 36, 446-451. [CrossRef] [PubMed]

16. World Health Organization. The Ottawa Charter for Health Promotion; World Health Organization: Ottawa, ON, Canada, 1986.

17. Vaz, O.M.; Ellingson, M.K.; Weiss, P.; Jenness, S.M.; Bardají, A.; Bednarczyk, R.A.; Omer, S.B. Mandatory vaccination in Europe. Pediatrics 2020, 145. [CrossRef] [PubMed]

18. Wright, A.; Smith, K.E.; Hellowell, M. Policy lessons from health taxes: A systematic review of empirical studies. BMC Public Health 2017, 17. [CrossRef] [PubMed]

19. Teng, A.M.; Jones, A.C.; Mizdrak, A.; Signal, L.; Genç, M.; Wilson, N. Impact of sugar-sweetened beverage taxes on purchases and dietary intake: Systematic review and meta-analysis. Obes. Rev. 2019, 20, 1187-1204. [CrossRef]

20. Narodowy Instytut Zdrowia Publicznego-Państwowy Zakład Higieny Mandatory Vaccinations in Poland-History and Rationale. Available online: https://szczepienia.pzh.gov.pl/en/stories/mandatoryvaccinations-in-poland/ (accessed on 27 July 2020).

21. Czarkowski, M.P.; Kondej, B.; Staszewska-Jakubik, E.; Cielebąk, E. Vaccinations in Poland in 2018; NIZP-PZH: Warszawa, Poland, 2019.

22. Żuk, P.; Żuk, P.; Lisiewicz-Jakubaszko, J. The anti-vaccine movement in Poland: The socio-cultural conditions of the opposition to vaccination and threats to public health. Vaccine 2019, 37, 1491-1494. [CrossRef]

23. Biostat. Available online: https://www.biostat.com.pl/ (accessed on 22 June 2020).

24. Pelikan, J.M.; Röthlin, F.; Ganahl, K. Measuring comprehensive health literacy in general populations: Validation of Instrument, Indices and Scales of the HLS-EU Study. In Proceedings of the 6th Annual Health Literacy Research Conference, Rockville, MD, USA, 1 December 2014.

25. Norman, C.D.; Skinner, H.A. eHEALS: The eHealth literacy scale. J. Med. Internet Res. 2006, 8, e27. [CrossRef]

26. Duplaga, M.; Sobecka, K.; Wójcik, S. The reliability and validity of the telephone-based and online polish eHealth literacy scale based on two nationally representative samples. Int. J. Environ. Res. Public Health 2019, 16, 3216. [CrossRef] 
27. Larson, H.J.; Jarrett, C.; Eckersberger, E.; Smith, D.M.D.; Paterson, P. Understanding vaccine hesitancy around vaccines and vaccination from a global perspective: A systematic review of published literature, 2007-2012. Vaccine 2014, 32, 2150-2159. [CrossRef] [PubMed]

28. Eilers, R.; de Melker, H.E.; Veldwijk, J.; Krabbe, P.F.M. Vaccine preferences and acceptance of older adults. Vaccine 2017, 35, 2823-2830. [CrossRef] [PubMed]

29. Bertoncello, C.; Ferro, A.; Fonzo, M.; Zanovello, S.; Napoletano, G.; Russo, F.; Baldo, V.; Cocchio, S. Socioeconomic Determinants in Vaccine Hesitancy and Vaccine Refusal in Italy. Vaccines 2020, 8, 276. [CrossRef]

30. Czajka, H.; Czajka, S.; Biłas, P.; Pałka, P.; Jedrusik, S.; Czapkiewicz, A. Who or What Influences the Individuals' Decision-Making Process Regarding Vaccinations? Int. J. Environ. Res. Public Health 2020, 17, 4461. [CrossRef]

31. Nowak, G.; Cacciatore, M.; Len-Ríos, M. Understanding and Increasing Influenza Vaccination Acceptance: Insights from a 2016 National Survey of U.S. Adults. Int. J. Environ. Res. Public Health 2018, 15, 711. [CrossRef]

32. Lucyk, K.; Simmonds, K.A.; Lorenzetti, D.L.; Drews, S.J.; Svenson, L.W.; Russell, M.L. The association between influenza vaccination and socioeconomic status in high income countries varies by the measure used: A systematic review. BMC Med. Res. Methodol. 2019, 19, 1-23. [CrossRef] [PubMed]

33. Nor Mat, S.; Ismail, N.; Taib, S.; Faisal Ghazi, H.; Izuan Azhar, Z.; Saffree Jeffree, M.; Mohammed Nawi, A.; Rohaizat Hassan, M. A Review of Pneumococcal Vaccination Acceptance Factors of Pneumococcal Vaccination among Adult Population: A Systematic Review. Int. J. Public Health Res. 2018, 8, 1006-1014.

34. Mclaughlin, J.M.; Swerdlow, D.L.; Khan, F.; Will, O.; Curry, A.; Snow, V.; Isturiz, R.E.; Jodar, L. Disparities in uptake of 13-valent pneumococcal conjugate vaccine among older adults in the United States Disparities in uptake of 13-valent pneumococcal conjugate vaccine among older adults in the United States. Hum. Vaccines Immunother. 2019, 15. [CrossRef] [PubMed]

35. López, N.; Garcés-Sánchez, M.; Panizo, M.B.; Salamanca De La Cueva, I.; Artés, M.T.; Ramos, B.; Cotarelo, M. HPV knowledge and vaccine acceptance among European adolescents and their parents: A systematic literature review. Public Health Rev. 2020, 41, 10. [CrossRef] [PubMed]

36. Della Polla, G.; Pelullo, C.P.; Napolitano, F.; Angelillo, I.F. HPV vaccine hesitancy among parents in Italy: A cross-sectional study. Hum. Vaccin. Immunother. 2020. [CrossRef]

37. Lorini, C.; Santomauro, F.; Donzellini, M.; Capecchi, L.; Bechini, A.; Boccalini, S.; Bonanni, P.; Bonaccorsi, G. Health literacy and vaccination: A systematic review. Hum. Vaccin. Immunother. 2018, 14, 478-488. [CrossRef] [PubMed]

38. Amit Aharon, A.; Nehama, H.; Rishpon, S.; Baron-Epel, O. Parents with high levels of communicative and critical health literacy are less likely to vaccinate their children. Patient Educ. Couns. 2017, 100, 768-775. [CrossRef] [PubMed]

39. Veldwijk, J.; Van Der Heide, I.; Rademakers, J.; Schuit, A.J.; Ardine De Wit, G.; Uiters, E.; Lambooij, M.S. Preferences for Vaccination: Does Health Literacy Make a Difference? Med. Deciion Mak. 2015, 35, 948-958. [CrossRef] [PubMed]

40. Pati, S.; Feemster, K.A.; Mohamad, Z.; Fiks, A.; Grundmeier, R.; Cnaan, A.; Pati, S.; Mohamad Á A Fiks Á R Grundmeier, Á.Z.; Mohamad, Z.; Fiks, A.; et al. Maternal Health Literacy and Late Initiation of Immunizations Among an Inner-City Birth Cohort. Matern Child Health J. 2011, 15, 386-394. [CrossRef] [PubMed]

41. Johri, M.; Subramanian, S.V.; Sylvestre, M.P.; Dudeja, S.; Chandra, D.; Koné, G.K.; Sharma, J.K.; Pahwa, S. Association between maternal health literacy and child vaccination in India: A cross-sectional study. J. Epidemiol. Community Health 2015, 69. [CrossRef]

42. Bennett, I.M.; Chen, J.; Soroui, J.S.; White, S. The contribution of health literacy to disparities in self-rated health status and preventive health behaviors in older adults. Ann. Fam. Med. 2009, 7, 204-211. [CrossRef]

43. White, S.; Chen, J.; Atchison, R. Relationship of preventive health practices and health literacy: A national study. Am. J. Health Behav. 2008, 32, 227-242. [CrossRef]

44. Lee, H.Y.; Kwon, M.; Vang, S.; Dewolfe, J.; Kim, N.K.; Lee, D.K.; Yeung, M. Disparities in Human Papillomavirus Vaccine Literacy and Vaccine Completion Among Asian American Pacific Islander Undergraduates: Implications for Cancer Health Equity. J. Am. Coll. Health 2015, 63, 316-323. [CrossRef] 
45. Moran, M.B.; Chatterjee, J.S.; Frank, L.B.; Murphy, S.T.; Zhao, N.; Chen, N.; Ball-Rokeach, S. Individual, Cultural and Structural Predictors of Vaccine Safety Confidence and Influenza Vaccination Among Hispanic Female Subgroups. J. Immigr. Minor. Health 2017, 19, 790-800. [CrossRef]

46. Castro-Sánchez, E.; Vila-Candel, R.; Soriano-Vidal, F.J.; Navarro-Illana, E.; Díez-Domingo, J. Influence of health literacy on acceptance of influenza and pertussis vaccinations: A cross-sectional study among Spanish pregnant women Foundation for the Promotion of Health and Biomedical Research in the Valencian Region. BMJ Open 2018, 8, 22132. [CrossRef]

47. Zhang, F.; Or, P.P.L.; Chung, J.W.Y. The effects of health literacy in influenza vaccination competencies among community-dwelling older adults in Hong Kong. BMC Geriatr. 2020, 20, 103. [CrossRef] [PubMed]

48. Dumit, E.M.; Novillo-Ortiz, D.; Contreras, M.; Velandia, M.; Danovaro-Holliday, M.C. The use of eHealth with immunizations: An overview of systematic reviews. Vaccine 2018, 36, 7923-7928. [CrossRef] [PubMed]

49. Britt, R.K.; Collins, W.B.; Wilson, K.M.; Linnemeier, G.; Englebert, A.M. The Role of eHealth literacy and HPV vaccination among young adults: Implications from a planned behavior approach. Commun. Res. Rep. 2015, 32. [CrossRef]

50. Britt, R.K.; Collins, W.B.; Wilson, K.; Linnemeier, G.; Englebert, A.M. EHealth literacy and health behaviors affecting modern college students: A pilot study of issues identified by the American college health association. J. Med. Internet Res. 2017, 19, e392. [CrossRef] [PubMed]

51. Aharony, N.; Goldman, R. E-Health Literacy and the Vaccination Dilemma: An Israeli Perspective. Available online: http://informationr.net/ir/22-2/paper751.html (accessed on 28 June 2020).

52. Muturi, N. Communication Research Reports eHealth literacy and the motivators for HPV prevention among young adults in Kenya. Commun. Res. Rep. 2020. [CrossRef]

53. Neter, E.; Brainin, E. Association Between Health Literacy, eHealth Literacy, and Health Outcomes Among Patients with Long-Term Conditions. Eur. Psychol. 2019, 24, 68-81. [CrossRef]

54. Chong, Y.Y.; Cheng, H.Y.; Chan, H.Y.L.; Chien, W.T.; Wong, S.Y.S. COVID-19 pandemic, infodemic and the role of eHealth literacy. Int. J. Nurs. Stud. 2020, 108, 103-644. [CrossRef]

55. Morley, B.; Martin, J.; Niven, P.; Wakefield, M. Health Public Policy Public opinion on food-related obesity prevention policy initiatives. Health Promot. J. Aust. 2012, 23, 86-91. [CrossRef]

56. Comans, T.; Moretto, N.; Byrnes, J. Public Preferences for the Use of Taxation and Labelling Policy Measures to Combat Obesity in Young Children in Australia. Int. J. Environ. Res. Public Health 2017, 14, 324. [CrossRef]

57. Sainsbury, E.; Hendy, C.; Magnusson, R.; Colagiuri, S. Public support for government regulatory interventions for overweight and obesity in Australia. BMC Public Health 2018, 18, 1-11. [CrossRef]

58. Farrell, L.C.; Moore, V.M.; Warin, M.J.; Street, J.M. Why do the public support or oppose obesity prevention regulations? Results from a South Australian population survey. Health Promot. J. Aust. 2019, 30, 47-59. [CrossRef] [PubMed]

59. Miller, C.L.; Dono, J.; Wakefield, M.A.; Pettigrew, S.; Coveney, J.; Roder, D.; Durkin, S.J.; Wittert, G.; Martin, J.; Ettridge, K.A. Are Australians ready for warning labels, marketing bans and sugary drink taxes? Two cross-sectional surveys measuring support for policy responses to sugar-sweetened beverages. BMJ Open 2019, 9, e027962. [CrossRef] [PubMed]

60. Richardson, T.E.; Yanada, B.A.; Watters, D.; Stupart, D.; Lamichhane, P.; Bell, C. What young Australians think about a tax on sugar-sweetened beverages. Aust. N. Z. J. Public Health 2019, 43, 63-67. [CrossRef]

61. Bélanger-Gravel, A.; Desroches, S.; Janezic, I.; Paquette, M.C.; De Wals, P. Pattern and correlates of public support for public health interventions to reduce the consumption of sugar-sweetened beverages. Public Health Nutr. 2019, 22, 3270-3280. [CrossRef] [PubMed]

62. Rivard, C.; Smith, D.; McCann, S.E.; Hyland, A. Taxing sugar-sweetened beverages: A survey of knowledge, attitudes and behaviours. Public Health Nutr. 2012, 15, 1355-1361. [CrossRef] [PubMed]

63. Gollust, S.E.; Barry, C.L.; Niederdeppe, J. Americans' opinions about policies to reduce consumption of sugar-sweetened beverages. Prev. Med. (Baltim) 2014, 63, 52-57. [CrossRef]

64. Donaldson, E.A.; Cohen, J.E.; Rutkow, L.; Villanti, A.C.; Kanarek, N.F.; Barry, C.L. Public support for a sugar-sweetened beverage tax and pro-tax messages in a Mid-Atlantic U.S. state. Public Health Nutr. 2015, 18, 2263-2273. [CrossRef]

65. Curry, L.E.; Rogers, T.; Williams, P.; Homsi, G.; Willett, J.; Schmitt, C.L. Public Attitudes and Support for a Sugar-Sweetened Beverage Tax in America's Heartland. Health Promot. Pract. 2018, 19, 418-426. [CrossRef] 
66. Petrescu, D.C.; Hollands, G.J.; Couturier, D.-L.; Ng, Y.-L.; Marteau, T.M. Public Acceptability in the UK and USA of Nudging to Reduce Obesity: The Example of Reducing Sugar-Sweetened Beverages Consumption. PLoS ONE 2016, 11, e0155995. [CrossRef]

67. Julia, C.; Méjean, C.; Vicari, F.; Péneau, S.; Hercberg, S. Public perception and characteristics related to acceptance of the sugar-sweetened beverage taxation launched in France in 2012. Public Health Nutr. 2015, 18, 2679-2688. [CrossRef]

68. Kwon, J.; Cameron, A.J.; Hammond, D.; White, C.M.; Vanderlee, L.; Bhawra, J.; Sacks, G. A multi-country survey of public support for food policies to promote healthy diets: Findings from the International Food Policy Study. BMC Public Health 2019, 19, 1-10. [CrossRef] [PubMed]

69. Eykelenboom, M.; van Stralen, M.M.; Olthof, M.R.; Renders, C.M.; Steenhuis, I.H. Public acceptability of a sugar-sweetened beverage tax and its associated factors in the Netherlands. Public Health Nutr. 2020, 1-11. [CrossRef] [PubMed]

70. Eykelenboom, M.; Van Stralen, M.M.; Olthof, M.R.; Schoonmade, L.J.; Steenhuis, I.H.M.; Renders, C.M. Political and public acceptability of a sugar-sweetened beverages tax: A mixed-method systematic review and meta-Analysis. Int. J. Behav. Nutr. Phys. Act. 2019, 16, 1-19. [CrossRef] [PubMed]

71. Bakacs, M.; Martos, E. Assessment of the Impact of a Public Health Product Tax; National Institute for Food and Nutrition Science Directorate General: Budapest, Hungary, 2015.

(C) 2020 by the author. Licensee MDPI, Basel, Switzerland. This article is an open access article distributed under the terms and conditions of the Creative Commons Attribution (CC BY) license (http://creativecommons.org/licenses/by/4.0/). 